\title{
Nonlinear Correlation analysis between Surface Resistivity and Hydraulic Characteristics of the Kabatini Well Field, Upper Lake Nakuru Basin, Kenya Rift
}

\author{
B.Sosi ${ }^{1}$, E. Cheboi ${ }^{2}$, C. Simiyu ${ }^{3}$ \\ ${ }^{I}$ Department of Natural Resources, Egerton University, Kenya, \\ ${ }^{2}$ Department of Natural Resources, Egerton University, Kenya, \\ ${ }^{3}$ National Oil Corporation of Kenya, Nairobi,
}

\begin{abstract}
The purpose of the study was to find and examine correlation relationships between field-scale hydraulic parameters and pore-scale geo-electrical parameter controlling groundwater occurrence in Kabatini aquifer of Upper Lake Nakuru Basin, Kenya. The study has taken under consideration priori published resistivity sounding and hydrological parameters and depth of water table from drill siteswhich is used to constrain ambiguity of interpretation.

An attempt has been made to derive general functional relationships between hydraulic parameters and geo-electric property of the aquifer.The observed hydraulic data from pumping test is correlated nonlinearly with aquifer electrical resistivity. The formation resistivity factor was found vary partially with pore volume and pore surface distribution. Porosity as a function of aquifer resistivity was best defined by a negative power law function, whereas transmissivity dependence on resistivity was found to bear a positive power law.

The aquifer parameters information thus obtained from resistivitysounding and pumpingtest data can be used for optimal management and assessment of groundwater resources.
\end{abstract}

Keywords: Geo-electric resistivity, Hydraulic characteristics, Nonlinear Correlation Analysis, Pumping test

\section{Introduction}

The empirical relations between aquifer parameters and resistivity are established for transforming resistivity distribution into hydraulic parameters of aquifers. Studies by [1], [2], [3], [4], [5] and [6] have shown that qualitative and occasionally quantitative relationships can often be found between geophysical and hydrogeological attributes. This is particularly in regard to lithology and hydraulic conductivity (K) from electrical resistivitydata.

Correlations between aquifer characteristics and electrical resistivity of the rocks have been studied and reviewed by many authors [7], [8], [9], [10] and [11]. Relationships between aquifer and geophysical parameters deduced by some of these researches are based on assumption that within the area of interest, geology and ground water quality remains fairly constant. For instance, studies by [7], [9] and [10] have analysed the correlation between aquifer and geoelectrical parameters in both the saturated and unsaturated zones of the aquifers. From different geological settings, empirical geoelectrical studies [11] and [12] have revealed that log$\log$ linear relationships bearing either positive or negative gradients exist between these two data sets; depending on mineralogy of rocks, grain size distribution and pore-fluid chemistry.

The integrated approach used in this study, has enabled derivation of site-specific relationships between pore-scale geoelectric and field-scale hydraulics. These relationships have been the basis of interpretation of the influence pore-scale rock heterogeneity on availability of groundwater in the area. We unveil therefore some unique remarkable results pointing out the hydro-physical behavior controlling the interrelationships between hydrodynamics and electrical parameter. Based on the physics of the problem, this paper has echoed the need for a rigorous effort during estimation for purposes of confidence.

\section{Geoelectric Models of Porosity, Transmissivity and Hydraulic Conductivity}

[13] published computed values of hydraulic characteristics of the study area. These parameters include porosity, transmissivity and hydraulic conductivity (Table 1). His study also included a range of aquifer geoelectric properties such as aquifer resistivityand aquifer thickness. 
Table 1: Calculated porosity, transmissivity and hydraulic conductivity values forthe study area (Source: [13]

\begin{tabular}{|c|c|c|c|c|c|c|c|c|}
\hline Station & $\begin{array}{l}\text { Aquifer } \\
\text { Resistivity } \\
(\Omega-m)\end{array}$ & $\begin{array}{l}\text { Aquifer } \\
\text { Thickness, } b_{e}\end{array}$ & $\begin{array}{l}\text { Calculated } \\
\text { Formation } \\
\text { Factor, } F_{a}\end{array}$ & $\begin{array}{l}\text { Calculated } \\
\text { Porosity } \\
\emptyset=\left[\frac{1}{F_{a}}\right]^{4.02}\end{array}$ & $\begin{array}{l}\ln T=- \\
0.584\left(\ln F_{a}\right) \\
+2.054\end{array}$ & $\begin{array}{l}\text { Aquifer } \\
\text { Transmissivity, } \\
\left(\mathrm{m}^{3} / \mathrm{hr}\right)\end{array}$ & $\boldsymbol{T}$ & $\begin{array}{c}K=\frac{T}{b_{e}} \\
\left(m^{2} / h r\right)\end{array}$ \\
\hline $1 \mathrm{~W}, 0$ & 2.94 & 16.41 & 6.18367 & 61.8848 & 0.9882 & 2.6863 & & 0.1637 \\
\hline 0,0 & 51.85 & 21.92 & 0.35063 & 56.0517 & 2.6671 & 14.3981 & & 0.65685 \\
\hline $1 \mathrm{E}, 0$ & 83.8 & 34 & 0.21695 & 55.9181 & 2.948 & 19.0667 & & 0.56079 \\
\hline $2 \mathrm{E}, 0$ & 26.75 & 9.89 & 0.67963 & 56.3807 & 2.2799 & 9.776 & & 0.98847 \\
\hline $1 \mathrm{~W}, 1 \mathrm{~S}$ & 20.53 & 45.39 & 0.88553 & 56.5866 & 2.1251 & 8.3739 & & 0.18449 \\
\hline $0,1 \mathrm{~S}$ & 34.33 & 40.15 & 0.52957 & 56.2307 & 2.4259 & 11.3122 & & 0.28175 \\
\hline $1 \mathrm{E}, 1 \mathrm{~S}$ & 18.04 & 70.57 & 1.00776 & 56.7089 & 2.0495 & 7.7638 & & 0.11002 \\
\hline $2 \mathrm{E}, 1 \mathrm{~S}$ & 55.03 & - & 0.33037 & 56.0315 & 2.7019 & 7.9401 & & - \\
\hline $1 \mathrm{~W}, 2 \mathrm{~S}$ & 15.4 & - & 1.18052 & 56.8816 & 1.9569 & 7.0775 & & - \\
\hline $0,2 S$ & 96.24 & - & 0.1889 & 55.89 & 3.0289 & 20.6748 & & - \\
\hline $1 \mathrm{E}, 2 \mathrm{~S}$ & 8.46 & 36.27 & 2.14894 & 57.85 & 1.6065 & 4.9853 & & 0.13745 \\
\hline $2 \mathrm{E}, 2 \mathrm{~S}$ & 20.9 & 36.81 & 0.86986 & 56.571 & 2.1356 & 8.4618 & & 0.22988 \\
\hline $1 \mathrm{~W}, 3 \mathrm{~S}$ & 14.12 & 86.2 & 1.28754 & 56.9886 & 1.9062 & 6.7272 & & 0.07804 \\
\hline $0,3 \mathrm{~S}$ & 16.97 & 50.39 & 1.0713 & 56.7724 & 2.0137 & 7.491 & & 0.14866 \\
\hline $1 \mathrm{E}, 3 \mathrm{~S}$ & 33.93 & 20 & 0.53581 & 56.2369 & 2.419 & 11.2349 & & 0.56175 \\
\hline $2 E, 3 S$ & 32.23 & 57.71 & 0.56407 & 56.2652 & 2.389 & 10.9021 & & 0.18891 \\
\hline
\end{tabular}

\section{Relationship between Intepreted Layer Resistivity and Borehole Lithology}

Owing to the complicated factors that affect resistivity values, the lithology and water quality effects cannot be discriminated exclusively by the geoelectric resistivity data. Therefore, [14] in [15] strongly recommend a correlation between real wells lithology data and the electrical field data for purposes of effective use hydrogeologic studies.

Integration of geoelectrical data in hydrogeology was based on the utilization of the dependence of rock resistivity on their lithology and the mineralization of water filling the pores, since both the soil material and the saturating water influence measured resistivity. The study considered a rock sample as a three component system distinct in terms of its composition, microstructure and interfacial effects; properties which fluid saturated electrical conduction depend on. A correlation analysis was therefore carried out between borehole lithology and observed resistivity log (Table 2). Borehole log information matched approximately well with the VES log because Water Struck Level (WSL) at borehole 1 is $58 \mathrm{~m}$. The borehole is located adjacent to station $1 \mathrm{E}, 0$.

Table 2: Correlation between lithologic characteristics at Borehole 1 and geoelectrical logs adjacent to VES station 1E,O (modified after [13]).

Borehole Geologic Log VES Log

\begin{tabular}{|c|c|c|c|c|}
\hline $\operatorname{Depth}(\mathrm{m})$ & RockType & $\operatorname{Depth}(\mathbf{m})$ & $\begin{array}{l}\text { Resistivity } \\
(\Omega-m)\end{array}$ & $\begin{array}{l}\text { Resistivity } \\
\text { comparison }\end{array}$ \\
\hline $0-4$ & $\begin{array}{l}\text { Brownish white loose soils and } \\
\text { gravel cemented byclayand ash }\end{array}$ & $0-4.5$ & $40.194-156.829$ & Low to High \\
\hline $4-8$ & $\begin{array}{l}\text { Loose medium brown graded coarse } \\
\text { sands and gravel cemented by } \\
\text { argillaceous material }\end{array}$ & $7.01-12.8$ & 61.613 & Moderate \\
\hline $8-16$ & $\begin{array}{l}\text { Pale brownish (buff) tuff with a thin } \\
\text { layer of sediments from } 10-12 \mathrm{~m} \text { depth }\end{array}$ & $12.8-20$ & 40.82 & Low \\
\hline $16-20$ & $\begin{array}{l}\text { Loose sediments of clay }(20 \%) \text {, sand } \\
(30 \%) \text { and gravel }(30 \%) \text { with trachyte } \\
\text { and phonolite-clasts }\end{array}$ & $20.01-36$ & $67.371-165.304$ & Moderate to High \\
\hline $20-26$ & $\begin{array}{l}\text { Buff white tuff (at the top) and medium } \\
\text { to dark grey ash at the bottom }\end{array}$ & & & \\
\hline $26-32$ & $\begin{array}{l}\text { Medium dark grey tuff and ash with } \\
\text { few hard rock fragments and white } \\
\text { patches of feldspar and ash }\end{array}$ & & & \\
\hline $32-34$ & $\begin{array}{l}\text { Dark yellowish tuff with few medium } \\
\text { to dark grey patches }\end{array}$ & & & \\
\hline
\end{tabular}




\begin{tabular}{|c|c|c|c|c|}
\hline $34-62$ & $\begin{array}{l}\text { Weathered erosional horizon followed } \\
\text { underlain by darkish basalt rock } \\
\text { composed mafic minerals and } \\
\text { subordinate quartz }\end{array}$ & $36.02-59.83$ & 142.246 & High \\
\hline $62-66$ & $\begin{array}{l}\text { Medium to slightly dark-grey volcanic } \\
\text { ash with lapith fragments (approx.1- } \\
2 \mathrm{~cm} \text { in size) }\end{array}$ & \multirow[t]{7}{*}{$59.83-106.91$} & \multirow[t]{7}{*}{80.08} & \multirow[t]{7}{*}{ Moderate resistivity } \\
\hline $66-76$ & $\begin{array}{l}\text { Light grey pumiceous horizon with } \\
\text { few rounded loose gravels }\end{array}$ & & & \\
\hline $76-78$ & $\begin{array}{l}\text { Medium grey rhyolite with obsidic } \\
\text { fragments }\end{array}$ & & & \\
\hline $78-80$ & Light tunic white tuff & & & \\
\hline $80-92$ & $\begin{array}{l}\text { Loose to cemented rounded clasts } \\
\text { composed of pumice pebbles, sands } \\
\text { and occasionally cemented by } \\
\text { brownish mud }\end{array}$ & & & \\
\hline $92-100$ & $\begin{array}{l}\text { Dark grey to black, tough } \\
\text { moderately weathered rock with glassy } \\
\text { sandstone phenocrysts }\end{array}$ & & & \\
\hline $100-106$ & $\begin{array}{l}\text { Brownish weathered rounded clasts of } \\
\text { dark grey to black phonolite }\end{array}$ & & & \\
\hline $106-128$ & $\begin{array}{l}\text { Medium grey highly felsic trachyte } \\
\text { (tough rock) }\end{array}$ & $>106.91$ & 16.8 & $\begin{array}{l}\text { Very low resistivity } \\
\text { (the horizon of buried } \\
\text { river channel) }\end{array}$ \\
\hline $128-134$ & $\begin{array}{l}\text { Grayish white tuff, not strongly } \\
\text { indurated, and mixed with reddish mud }\end{array}$ & & & \\
\hline
\end{tabular}

Though most of the geological data from existing boreholes were unavailable, the information obtained from the available (lithological log adjacent to VES station 0,1E) showed that the subsurface materials are basically clay, clayey silt, and fine to medium sand, coarse sand, pebbles, boulders, tuff and lava.

Electrical conductivity (EC) of the waters was observed to be approximately $550 \mu \mathrm{S} / \mathrm{cm}$ and its reciprocal - the resistivity $\left(\rho_{\mathrm{w}}\right)$, is $18.18 \mathrm{Ohm}$ meter.

Experimental studies by [16] in NW Europe have demonstrated that a correlation exists between formation resistivity factor $F_{a}$ and the particle size (Table 3) of sedimentary materials. This general relationship has been adopted as a rough guide, because it fitted well with borehole evidence and the calculated $\mathrm{F}$ values for BH1 are shown in Table 4 (showing Resistivity Ranges for geologic materials in BH1).

Table 3: Relationship between $F$ values and grain sizes from various studies in NW Europe (source: [16].

\begin{tabular}{ll}
\hline \hline $\boldsymbol{F}_{\boldsymbol{a}}$ & Particle Size \\
\hline 1 & Clays \\
$1.5-2$ & Sandy clays \\
$2-2.5$ & Silt and clay sands \\
3 & Fine sands \\
$4-5$ & Medium coarse sands \\
$6-7$ & Coarse sands \\
$>8$ & $>8$ Very coarse sands and pebbles \\
\hline \hline
\end{tabular}

Dependence of hydraulic and electric flow gradient on the lithological character (rock type) has therefore been computed using Archie's law [17] (1) in [18]:

$\rho_{f}=F_{a} \rho_{w}$

where the resistivity of the saturated rock, $\rho_{f}$ is directly proportional to resistivity of the water filling the pores, $\rho_{w}$ and $F_{a}$ is the formation factor.

Table 4:Computed $F_{a}$ values through BH lcomputed using (1) integrated with studies of [16]

\begin{tabular}{|c|c|c|c|c|}
\hline \multicolumn{4}{|c|}{$\begin{array}{l}\text { Lithological interpretation of station 0,E based on Archie's Law and } \\
\text { Sporry (2001) }\end{array}$} & \multirow[t]{2}{*}{$\begin{array}{l}\text { Lithological interpretation according to } \\
\text { borehole } 1 \mathrm{log} \text { near station } 0,1 \mathrm{E}\end{array}$} \\
\hline $\begin{array}{l}\text { Geo-electric layer } \\
\text { depth }\end{array}$ & $\rho_{f}$ & $F_{a}$ & GRAIN-SIZE & \\
\hline 0.787 & 40.195 & 2.210946 & Silt and clay sand & $\begin{array}{l}\text { Brownish white loose soils and gravel } \\
\text { cemented by clay and ash }\end{array}$ \\
\hline 1.771 & 120.162 & 6.609571 & Coarse sands & $\begin{array}{l}\text { Pale brownish (buff) tuff with a thin layerof } \\
\text { sediments from } 10-12 \mathrm{~m} \text { depth }\end{array}$ \\
\hline 3.154 & 237.341 & 13.05506 & $\begin{array}{r}\text { coarse } \\
\text { and }\end{array}$ & $\begin{array}{l}\text { Loose sediments of clay }(20 \%) \text {, sand }(30 \%) \\
\begin{array}{lll}\text { and gravel } & (30 \%) & \text { withtrachyte and }\end{array}\end{array}$ \\
\hline
\end{tabular}




\begin{tabular}{|c|c|c|c|c|}
\hline \multirow[b]{2}{*}{4.931} & \multirow[b]{2}{*}{156.829} & \multirow[b]{2}{*}{8.626458} & & \multirow[b]{2}{*}{$\begin{array}{l}\text { Buff white tuff (at the top) and medium to dark } \\
\text { grey lapilli-ash at the bottom }\end{array}$} \\
\hline & & & $\begin{array}{lr}\text { Very } & \text { coarse } \\
\text { sands } & \text { and } \\
\text { pebbles } & \end{array}$ & \\
\hline 7.033 & 61.613 & 3.389054 & Fine sands & $\begin{array}{l}\text { Medium dark grey tuff and ash with few hard } \\
\text { rock fragments and white patches of feldspar } \\
\text { and ash }\end{array}$ \\
\hline 12.911 & 40.818 & 2.245215 & $\begin{array}{l}\text { Silt and clay } \\
\text { sands }\end{array}$ & $\begin{array}{l}\text { Dark yellowish tuff with few medium to dark } \\
\text { grey patches }\end{array}$ \\
\hline 19.64 & 67.371 & 3.705776 & Fine sands & $\begin{array}{l}\text { Weathered erosional horizon } \\
\text { followed immediately by dark almost black } \\
\text { basalt rock composed of a layer dominated by } \\
\text { mafic minerals and subordinate quartz }\end{array}$ \\
\hline 34.875 & 165.304 & 9.092629 & $\begin{array}{l}\text { Very co } \\
\text { sands } \\
\text { pebbles }\end{array}$ & $\begin{array}{l}\text { Medium to slightly dark grey volcanic ash with } \\
\text { lapith fragments (approx.1-2cm in size) }\end{array}$ \\
\hline 59.832 & 142.246 & 7.824312 & Coarse sands & $\begin{array}{l}\text { Light grey pumiceous horizon with few } \\
\text { rounded loose gravels }\end{array}$ \\
\hline 106.905 & 67.764 & 3.727393 & Fine sands & Medium grey rhyolite with obsidic fragments \\
\hline$>165$ & 21.759 & 1.196865 & Sandy clays & $\begin{array}{l}\text { Greyish white tuff, not strongly indurated, and } \\
\text { mixed with reddish mud }\end{array}$ \\
\hline
\end{tabular}

\section{The Empirical Statistical Correlation Analysis between Geoelctrical and Hydrogeologic Parameters}

Application of geoelectrical methods to estimate hydraulic parameters depends on the existence of a petrophysical relationship between electrical and hydraulic properties. Application of aquifers resistivity is particularly effective for estimating aquifer hydraulic conductivity $(\mathrm{K})$ because of the fundamental relation between hydraulic conductivity and electrical conductivity through their common dependence on porosity [19] in [15].

Based on the semi-empirical 'Hypothesis' of [17], that the formation factor is a function of porosity, bulky conductivity, and also dependent on groundwater water resistivity and cementation factor from which it's derived. An increase in formation resistivity factor, associated with an increase in the porosity (Fig.1), corresponds to an increase in the bulk conductivity (Fig.2). The study also validated observations [20] and [21] that effective porosity and effective permeability (indicated by Transmissivity) are related directly to each other (Fig.3). Thesignificance of this is that an augment in permeability (connected with an upsurge in porosity and anincrease in formation resistivity factor) is related to a decrease in the resistance horizontally (Fig.4). This explicates the expresscorrelationconnecting the groundwater transmissivity and the longitudinal unit conductance for the study area.

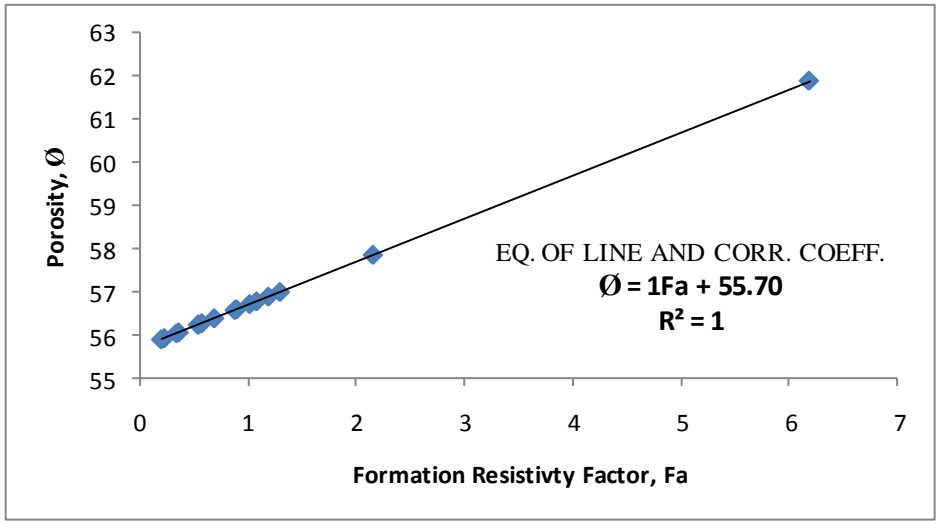

Fig. 1: Formation Resistivity factor versus Porosity of the aquiferous material 


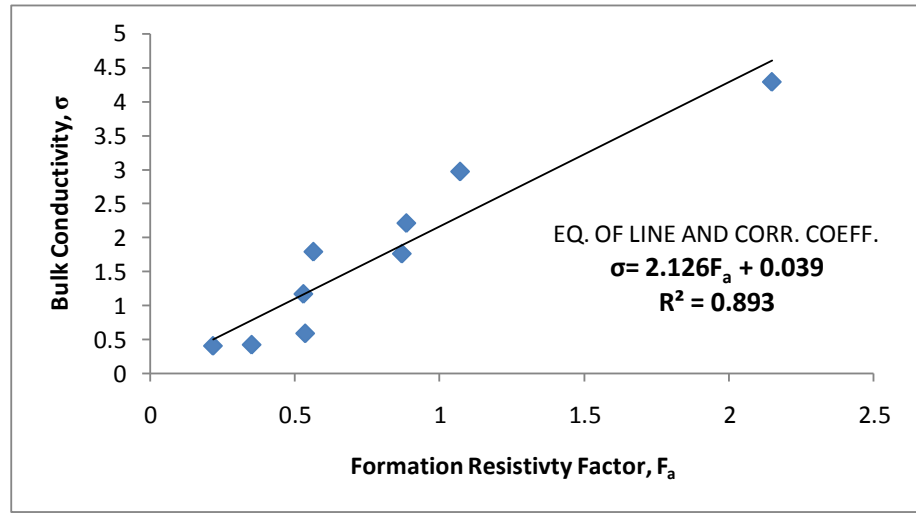

Fig.2: Formation Resistivity factor versus bulk conductivity

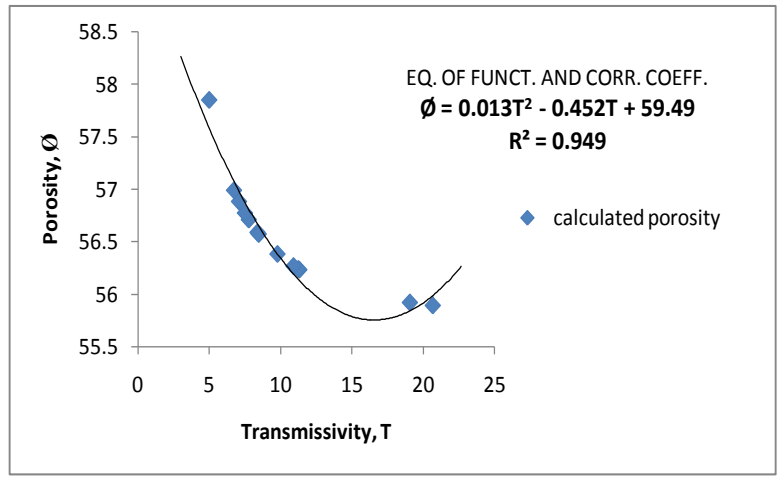

Fig.3: Aquifer Transmissivity versus Effective Porosity

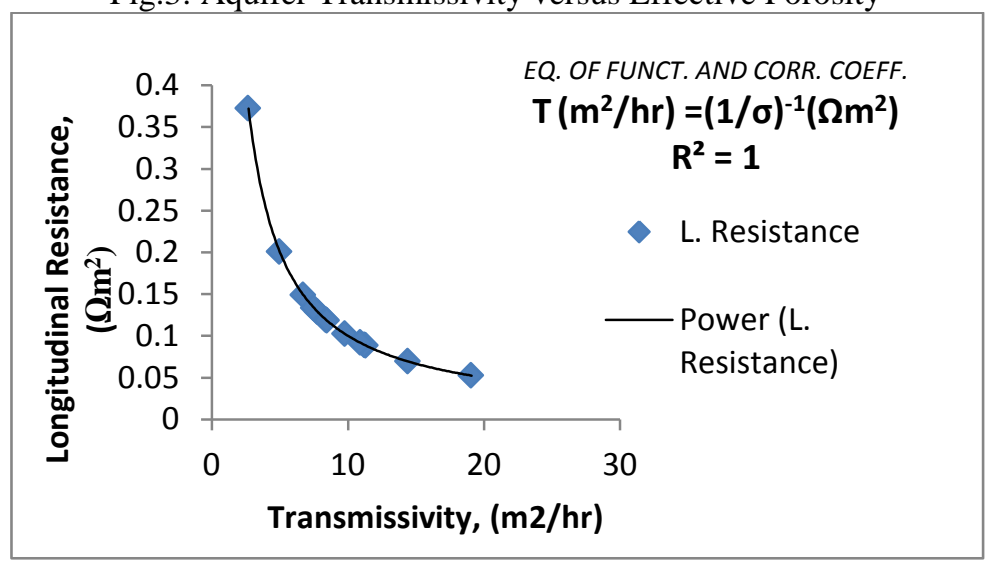

Fig. 4: Correlation analysis between field transmissivity and micro-scale longitudinal resistance An empirical relation (2):

$$
T\left(\frac{m^{2}}{h r}\right)=\left(\frac{1}{\sigma}\right) \mathrm{R}^{-1}\left(\Omega m^{2}\right)=\sigma \mathrm{S}\left(\Omega m^{-2}\right)
$$

where ois the aquifer conductivity, between Transmissivity, $\mathrm{T}$ and longitudinal resistance, $\mathrm{R}$ or longitudinal conductance, $\mathrm{S}$ is obtained by using regression techniques. This is practically a negative power law relation, within the range of values used, that is fluid potential (indicated by transmissivity) increases inversely with unit conductance horizontally. This observation suggests that the aquifer material is resistive in its transverse component; and both electrical and hydraulic flows are dominantly longitudinal in typical unit column of the aquifer; and the relationship is inverse. This observation is clearly validated by [22] who states that, "at a macroscopic scale, i.e., at a dimension corresponding to the depth of surface electrical sounding, the relationship between $\mathrm{K}$ and $\rho$ can be strongly controlled by the nature of the aquifer substratum".

For the current study, bulk conductivity was correlated with effective porosity. It was established that a positive natural log-log relationship results from mutual increase of bulk conductivity $(\sigma)$ with increasing porosity $(\varnothing)$ (Fig. 5). What this suggests is that the flow domain is dominated by low surface connectivity, 
saturated with conductive groundwater flowing within the pore volumes as one visualized by [1] and [5] in [23] conceptualized the pore geometry network of circular tubes, and randomly imposed heterogeneity by changing pore-size shrinkage factor. The product was a skewed pore-size distribution network. In the actual sense, this skewness occurs as a consequence of rock forming processes which tend to reduce the large pore spaces by a large amount and small pores by a small amount [23]. They showed that in the limit as bonds and bond shrinkage factors get large, power law relationships evolve from logarithmic ratios of porosity (Fig. 6 and Fig. 7).

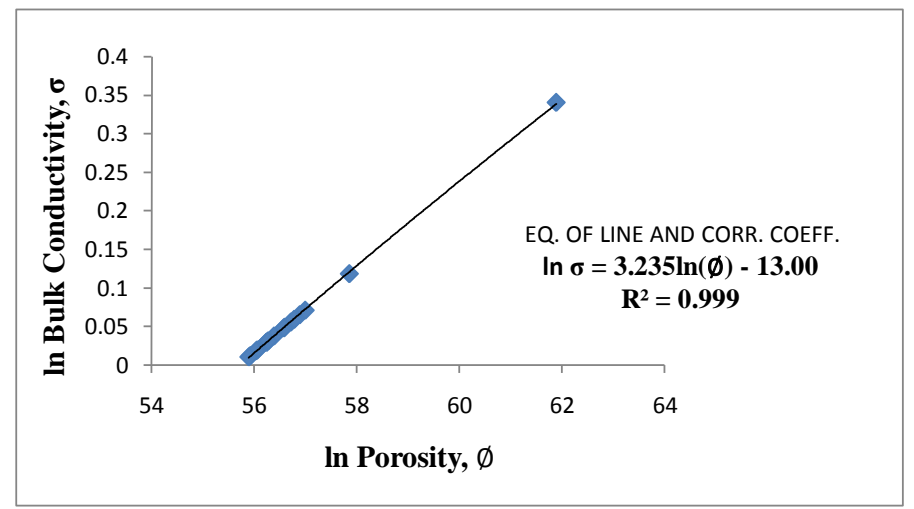

Figure 5: Log Bulk rock conductivity Versus log Effective Porosity.

It was found that for sufficient aperture volumes and fractures in rocks of the study area, porosity, $\emptyset$ as a function of aquifer resistivity, $\rho_{f}$ (Fig. 6) is best defined by a negativepower law function:

$$
\emptyset=61.37 \rho_{f}^{-0.02}
$$

This non linear negative power correlation between small scale electrical (VES readings) and large scale hydraulic parameters (porosity) means that movement of fluids in the aquiferous zone is through a network of skewed pore sizes and/or fracture traces well distributed in the flow medium as the one postulated by [23].

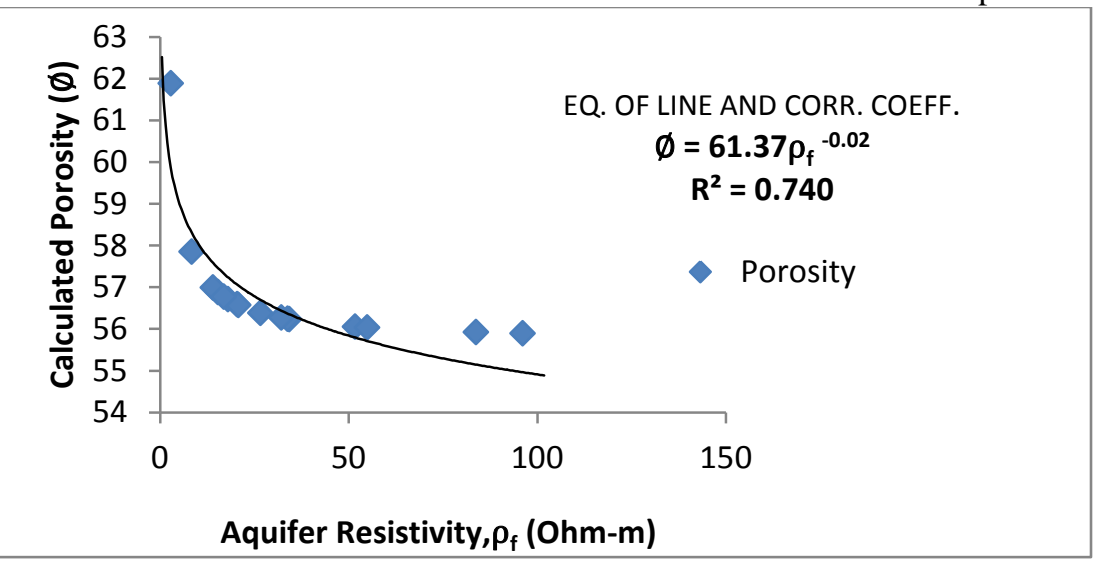

Fig. 6: Calculated porosity factor versus geoelectric resistivity. The graphical analysis compares between the field variations in Fig. 8 and Fig. 9.

As the two figures (Fig. 8 and Fig. 9) show inverse proportion in the two parameters, it is evident that decreasing porosity (pore volumes and fractures) within the aquifer zone reduces significantly the pore volume and/or fracture connection for water and direct current to flow [24]. In general terms, it is widely accepted that since a correlation exists between electrical and hydraulic parameters that larger connected pores would make for better flow characteristics for both groundwater and electric currents ([25] and [26]).

This approach is viable as both electrical flow and groundwater flow are channeled through interconnected pore volumes and pore-surfaces. Parameters describing this flow, namely hydraulic conductivity (Darcy"slaw) from hydrodynamics and electric conductivity (Ohm's law) from the resistivity method are a measure of interconnectedness of pore volumes (porosity). The negative correlation is therefore consistent with the interpretation of groundwater and electrical flow through pore volumes rather than clay surface conduction. Correspondingly, the interrelationship between longitudinal conductance and porosity (Fig. 14) is expected to exist under isotropic conditions.

Transmissivity (for water flux) dependence on geoelectric resistivity (for electric flux) was found to bear a positive power law (Fig. 7). The governing relation between variation in field-scale transmissivity (Fig. 12) and pore-scale geoelectric resistivity (Fig. 9) derived graphically is: 


$$
T=1.429 \rho \rho_{f} 0.585
$$

It is this expression that provides a general idea of the water producing capabilities of this aquifer from surfacial electrical methods.

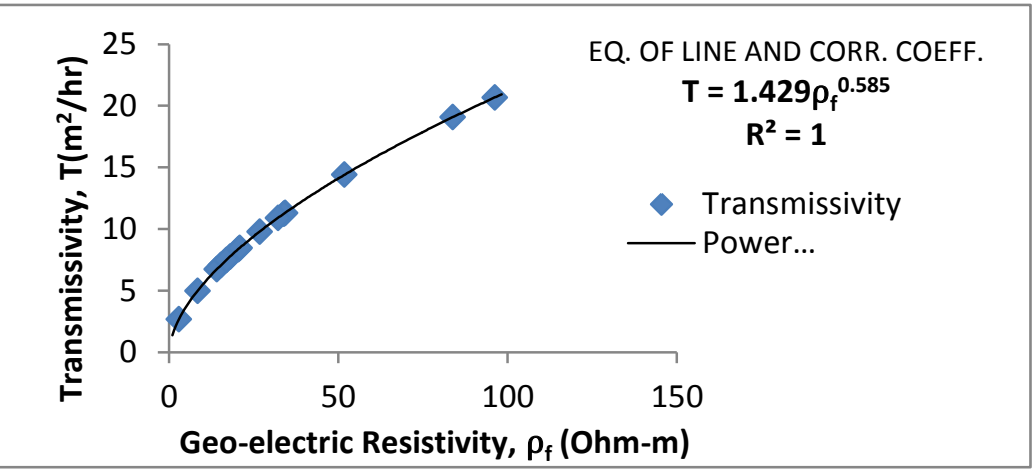

Fig. 7: Aquifer Transmissivity factor versus geoelectric resistivity. The graphical analysis compares between the field variations in transmissivivity (Fig. 12) and resistivity (Fig. 9).

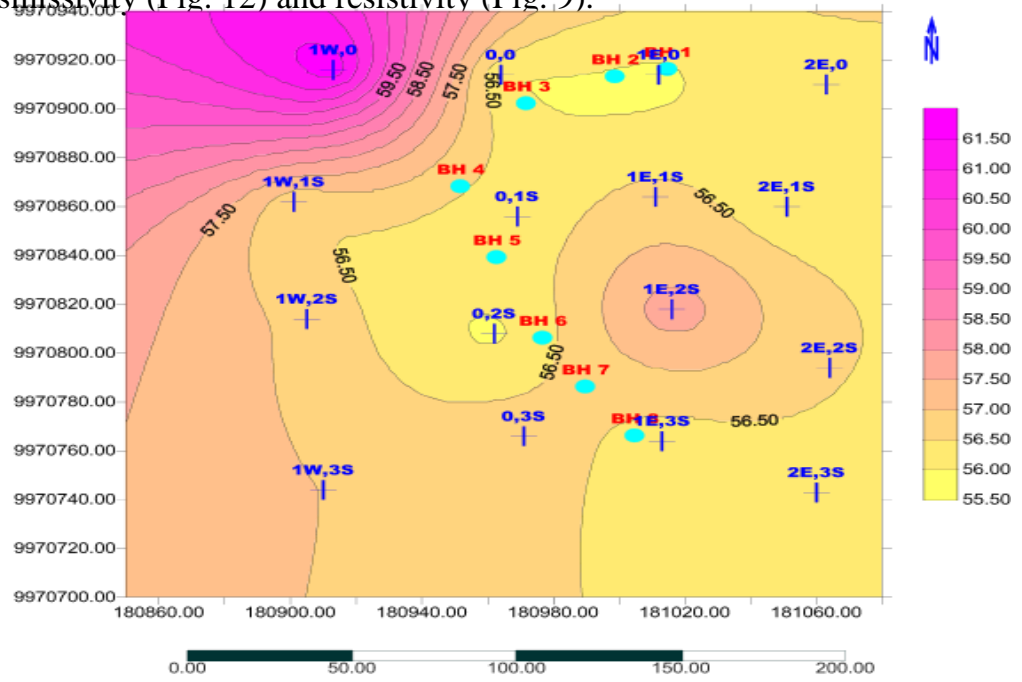

Fig. 8: Calculated porosity distribution across the study area using statistical kriging interpolation. Electric as well as hydraulic flow through connected pores is dominant on the northwestern portion of the aquifer.

Low values of porosity occurring dominantly in the eastern stretch of the study area (Fig. 8) may be defined at VES station $1 \mathrm{E}, 2 \mathrm{~S}$ as anisotropy introduced by sedimentation of fine clay matter [24].This conditionally locksup pore volumes to pave way for sufficient pore surface conduction. The sedimentation effect, besides causing anomalies in porosity, it may also alter Transmissivity (Fig. 12), crack orientation, turtuosity and texture.

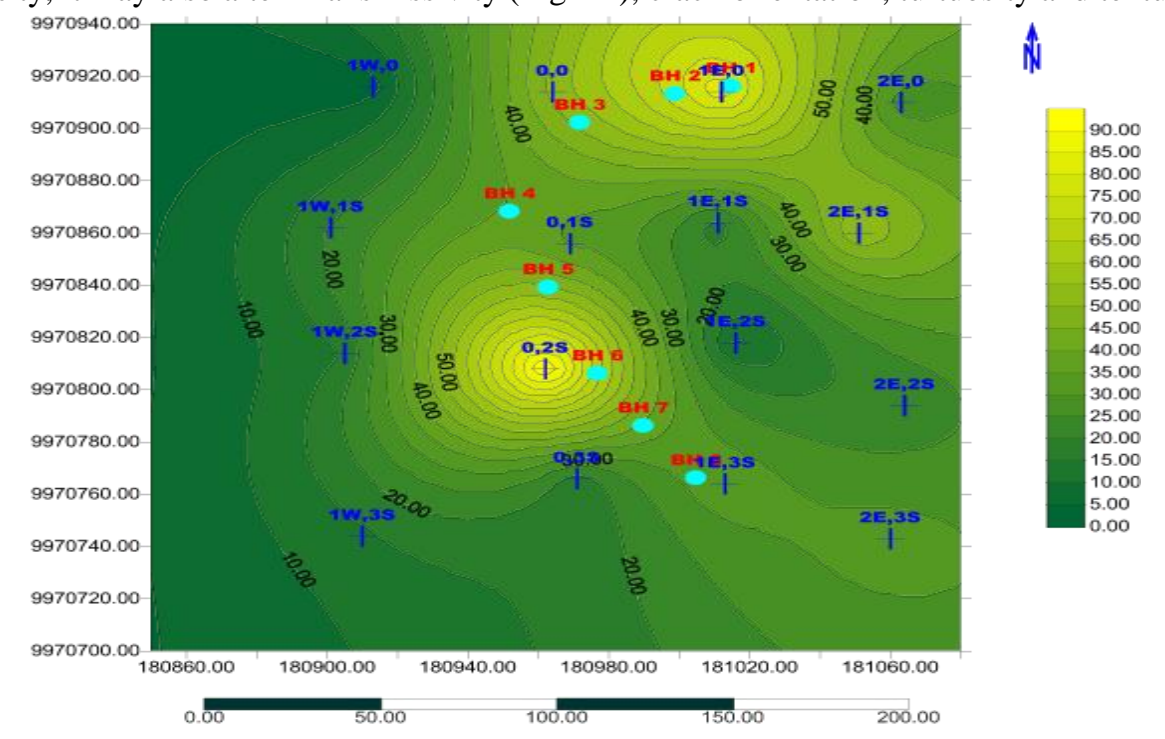


Fig. 9: Variation of the composite layer geoelectric resistivity parameter across the study area using ordinary kriging method

A comparison between statistically interpolated porosity distribution (Fig. 8) and composite layer resistivity (Fig. 9) showed that there is a general porosity low associated with relatively low geoelectric resistivity to the eastern portion of the study area which is only interrupted by a moderately low resistivity anomaly at station $1 \mathrm{E}$, $2 \mathrm{~S}$. This again may be attributed to interfacial effects between minerals and fluid which results in formation of electrochemical diffuse layer on mineral surfaces as one envisaged in [27].

The studies carried out by [28] and [29] indicated that fault structures control ground water movement in Upper Lake Nakuru basin. Their results, therefore, indicated that the aquifer in Kabatini is on a buried river channel at the eastern periphery of the well field.

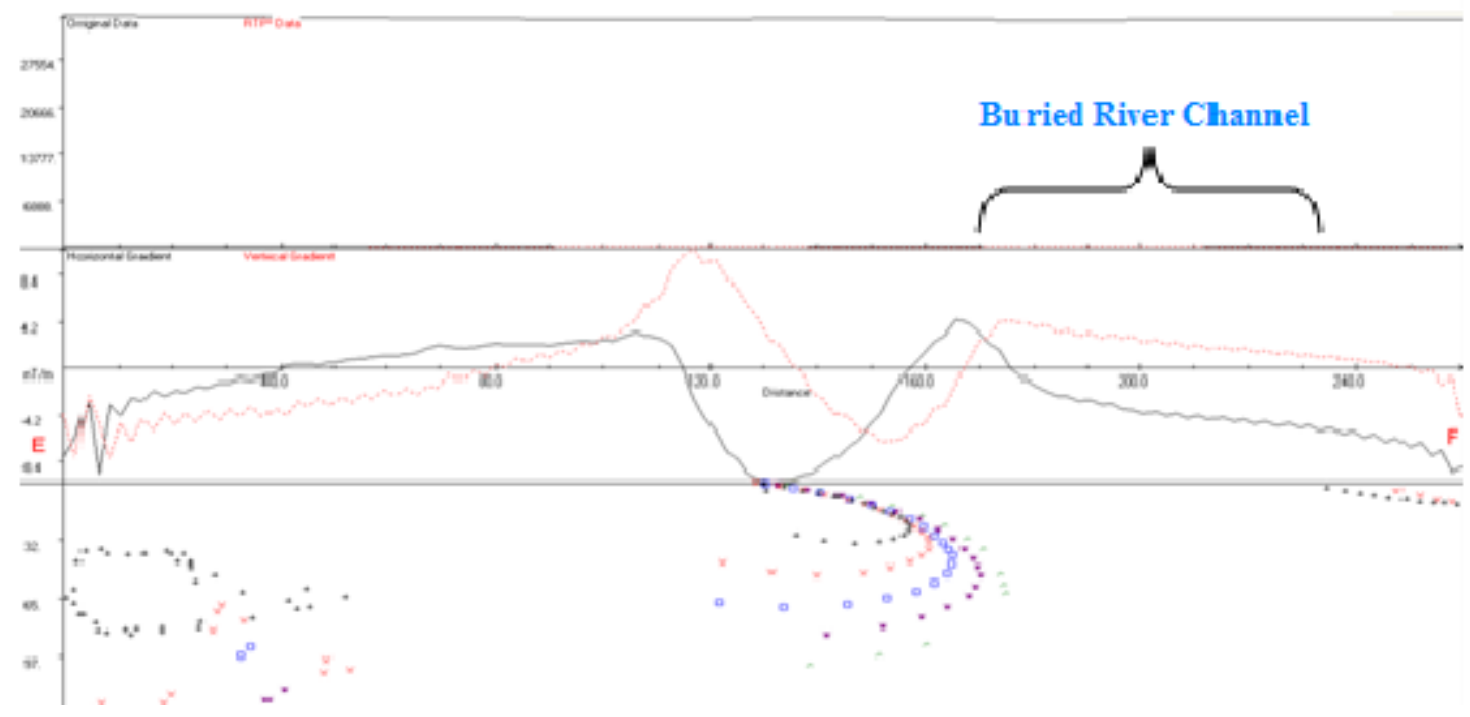

Fig. 10: Depth-to-magnetic sources by using program EUL. The wide gap in the eastern part of the aquifer marks the east-west extent of the buried fault/fracture zone occupied by Ngosur River (modified after; [26]).

The channel has been inferred as River Ngosur that flows in the approximate north - south direction. The low porosity- low resistivity at station $1 \mathrm{E}, 2 \mathrm{~S}$ could be the due to sediment deposition from the suggested river channel.

Apparent resistivity plots (Fig. 11) at $\mathrm{AB} / 2=70$ meters show a low resistivity anomaly in the eastern part that is concurrent with the axis of the buried river channel.

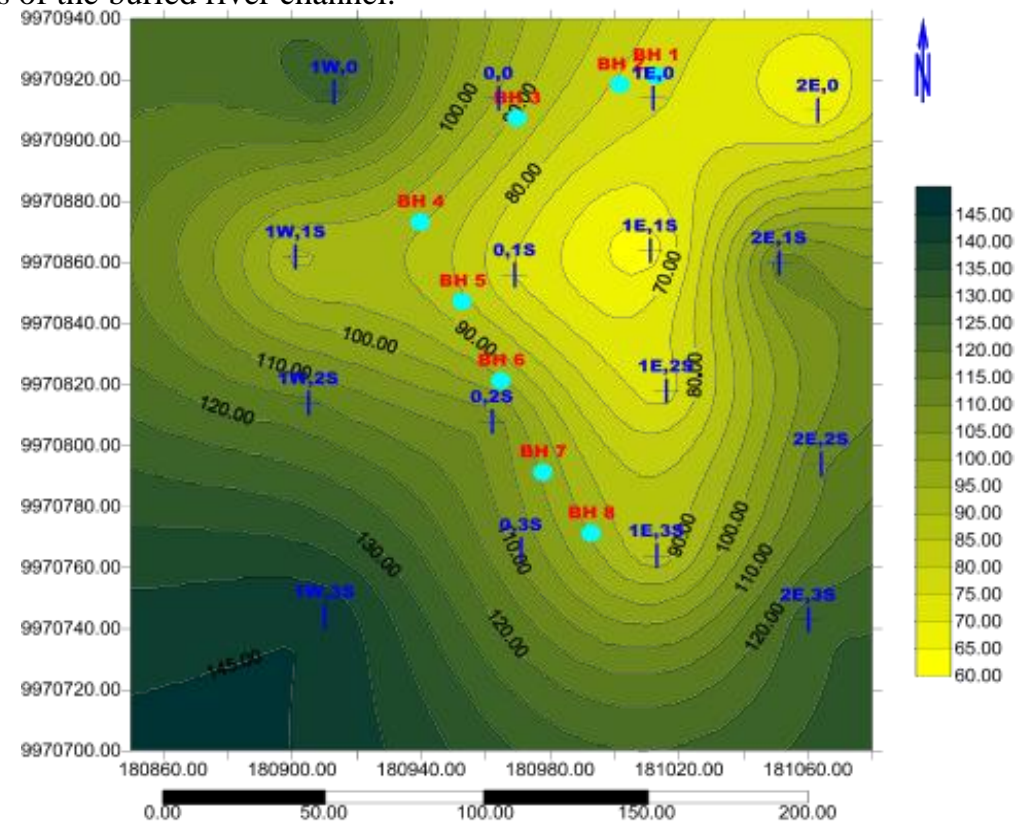

Fig. 11: The distribution of apparent resistivity in the subsurface at a depth $A B / 2=70$ metres. VES stations are marked $1 \mathrm{~W}, 0,0,0,1 \mathrm{E}, 0,2 \mathrm{E}, 0,1 \mathrm{~W}, 1 \mathrm{~S} \ldots \ldots \ldots \ldots \ldots \ldots \ldots \ldots \ldots \ldots \ldots \ldots \ldots \ldots . . .2 \mathrm{~S}$. 
When calculated values of transmissivity were interpolated (Fig. 12), it was observed that a direct proportion was evident in relation to the composite layer resistivity variation (Fig. 9).

What this pattern means is that the gradient of hydraulic head due to the river drives the water increasing the transmissivity across the pore surfaces of loose sediments of clay and weathered tuffs with few rounded loose gravels evident in the geologic logs (Table 1).

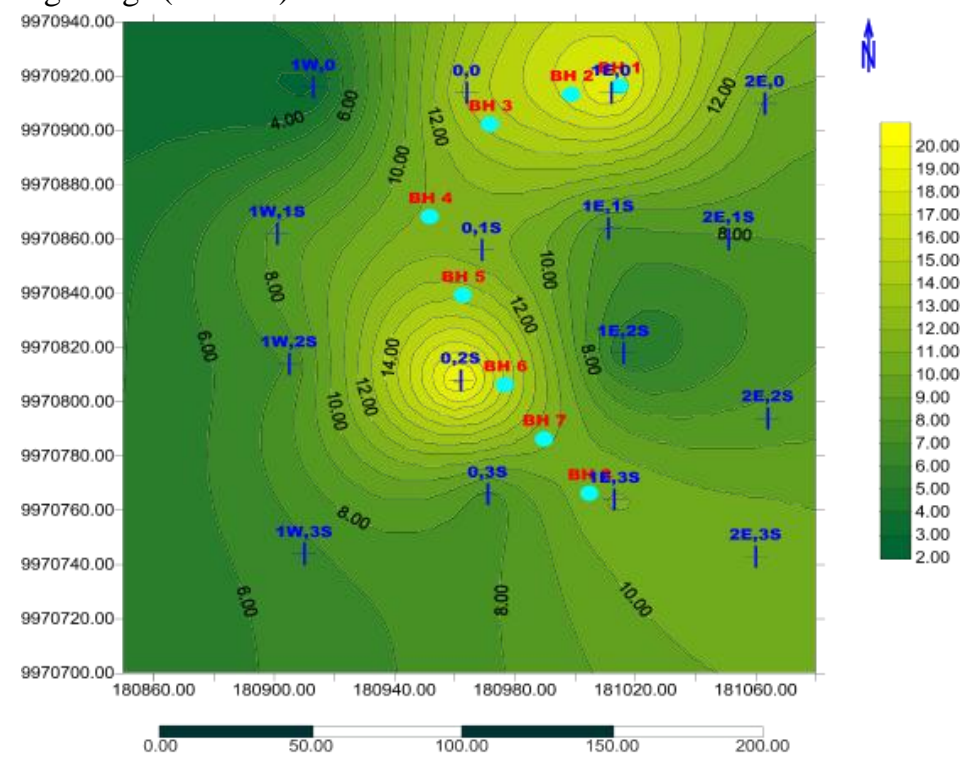

Fig. 12: Calculated transmissivity distribution across the study area using ordinary interpolation.

Comparison of field variation in computed transmissivity (Fig. 12) and geoelectric resistivity (Fig. 9) indicates the effect of groundwater abstraction. In the vicinity of boreholes, pumping increases transmissivity of the geologic formation and thus lowering formation storativity as indicated by the relatively high values of composite layer resistivity. In the studied field, groundwater potential is relatively high away from pumped sites but restricted to the mid- eastern portion of the aquifer rather than to the western stretch where geoelectric resistivity vectors are quite divergent probably due to paucity of sounding data (Fig. 9).

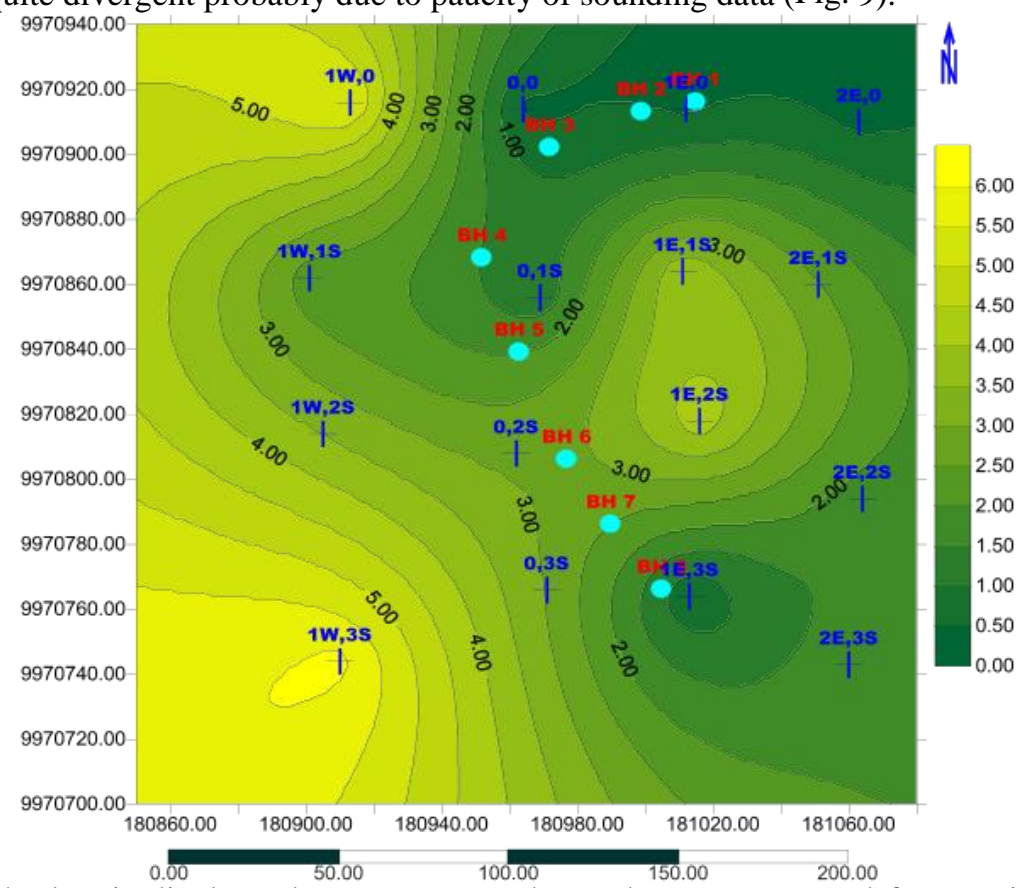

Fig. 13: Variation of the longitudinal conductance across the study area computed from resistivity sounding interpretation. Note the close relationship between the variation in longitudinal conductance parameter and variation in porosity in Fig. 8.

The geoelectric resistivity transforms of the study area have enabled in understanding the movement and retention of fluids and field-scale heterogeneity of the aquifer formation. It was observed that the variation in this parameter follows the field layout of boreholes. Since the deepest well is approximately 166 meters and that 
most wells do exploit the full thickness of the aquifer, then the preferred flow to the wells is essentially longitudinal to the confining layers as opposed to transverse flows perpendicular to confining layers. This indicates a highly resistive substratum in vertical component of the aquifer implying that longitudinal unit conductance is the dominant characteristic parameter in the electrical flow system [22].

The longitudinal conductance map (Fig. 13) of the confined aquifer was correlated with porosity distribution map (Fig. 14). Within the range of values used, the two parameters were best fitted by a polynomial relationship:

$$
\varnothing=0.159 \sigma^{2}-0.380 \sigma+56.37 .
$$

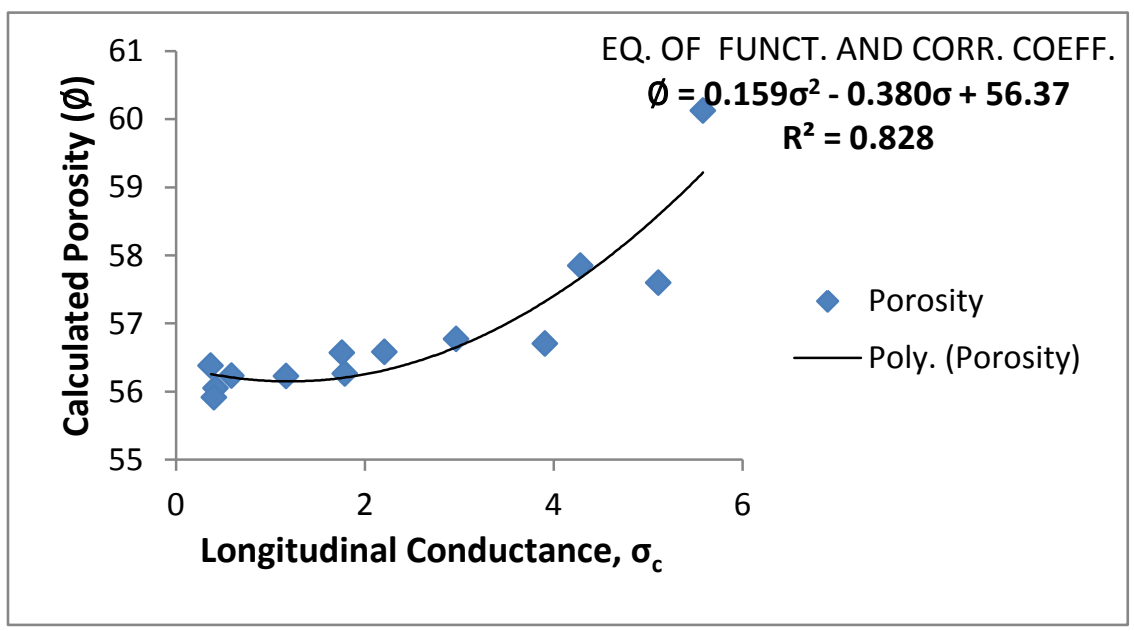

Fig. 14: Correlation analysis between variations in micro-scale longitudinal conductance and computed fieldscale aquifer porosity.

What this means is that although the flow within porous medium between the bounding layers is essentially longitudinal to the faces, it's highly influenced by lithological heterogeneities such as rock texture, weathering and rock saturation as well as lithology, mineralogy, size of grains, and size and shape of pores and pore channels. Since the factors that determine the value of rock conduction characteristics are fundamentally porosity and permeability, correlation between these constraints is often possible.

\section{Conclusions}

In summary what the study has achieved is derive general practical relationships between hydraulic parameters and geoelectric resistivity of the aquifer. The study has demonstrated the applicability of geoelectrical data in delineating and characterizing hydrogeological processes and properties of the aquifer. Empirical relations between aquifer parameters and resistivity are established for converting resistivity distribution into porosity (permeability), transmissivity and hydraulic conductivity of the aquifer. It is found that for sufficient pore volumes and fractures in rocks of the study area, porosity and transmissivity are best defined as power law functions of aquifer resistivity.

This characterization scheme was feasible as both electrical potential and groundwater channels through interconnected pore-spaces in the groundwater flow domain. Such interconnectedness of the pore volume (representing porosity) as may be described from the hydraulic conductivity and electrical conductivity of the pore fluid determine the flow. Hydraulic parameters are therefore a measure of the interconnection of pore volumes (porosity). Maps of the geoelectric resistivity, transmissivity and longitudinal conductance, porosity provided the means to identify areas where the aquiferous zone is prolific.

The integrated approach has enabled derivation of site-specific relationships between pore-scale geoelectric and field-scale hydraulic relations. These correlations have made it possible to gain insights into how pore - scale heterogeneity of rocks affects the movement of groundwater and electric current in the study area. However, it is paramount to note that these relationships may not be valid throughout the flow domain since they are not a function of hydrogeologic factors alone, but also data acquisition errors and survey array geometry. Nevertheless still, recognizing such qualitative relations are useful in groundwater studies, for example, if optimal locations of artificial recharge structures are to be sited. 


\section{Acknowledgements.}

Parts of the presented work were carried out as part of the Master of Science (Geology) Degree program. The realization of this research was funded by the University of Nairobi, Kenya. The authors also sincerely thank Prof. Justus O. Barongo, for providing some field equipments.

\section{References}

[1] P.C Heigold, R.H Gilkeson, K. Cartwright, and P.C Reid, Aquifer transmissivity from surficial electrical methods, Groundwater, 17, 1979, 330-345.

[2] W.K Kosinsky, and W.E Kelly, Geoelectrical soundings for predicting aquifer properties. Groundwater 19, 1981, 163-171.

[3] D Urish, Electrical resistivity-hydraulic conductivity relationships in glacial outwash aquifers, Water Resources research, 17(5), 1981, 1401-1408.

[4] G. Ponzini, A. Onstroman, and M. Molinari. Empirical relation between electrical transverse resistance and hydraulic transmissivity, Geoexploration Journal, 22, 1983, 1-15.

[5] R.K Frohlich, J.J Fisher and E. Summerly, Electric-hydraulic conductivity correlation in fractured crystalline bedrock: Central Landfill, Rhode Island, USA, Journal of Appl. Geophys, 35, 1996, 249-259.

[6] S Hubbard, and Y. Rubin, Hydrogeophysics: State-of-the-Discipline, EOS, 83(51), 2002, 602-606.

[7] S Niwas, and D.C Singhal, Estimation of aquifer transmissivity from Dar Zarrouk parameters in porous media, Journal of Hydrology, 50, 1981, 393-399.

[8] W.E Kelly, Geoelectrical sounding for estimating aquifer hydraulic conductivity, Groundwater Journal, 24, 1977b, 466-474

[9] Mozac, W.E Kelly, and I Landa, A hydrogeophysical model for relations between electrical and hydraulic properties of aquifers, Journal of Hydrology, 79, 1985, 1-19.

[10] P.D.C. Mbonu, J.O Ebeniro, C.O Ofoegbu, A.S. Ekine, Geoelectric sounding for the determination of aquifer characteristics in parts of the Umuahia area of Nigeria, Geophysics, 56(2), 1991, 284-291.

[11] D Huntley, Relationship between permeability and electrical resistivity in granular aquifers, Groundwater Journal, 24(4), 1987, 466-474.

[12] M. K. Odondi, Integrated approach utilizing geoelectric resistivity data to groundwater modelling in the hard rock terrains of the Jangaon watershed of India, doctoral diss., Jomo Kenyatta Uninersity of Agriculture and Technology, Nairobi, Kenya. 2009.

[13] B. Sosi, Hydraulic Characterization of the Kabatini Aquifer, Upper Lake Nakuru Basin, Kenya rift, Using Geophysical and Pumping Test Data, International Journal of Development and Sustainability, $X(X)$, 2013, (In Press).

[14] N.J George, V.I Obianwu and I.B Obot, Estimation of groundwater reserve in unconfined frequently exploited depth of aquifer using a combined surficial geophysical and laboratory techniques in The Niger Delta, South - South, Nigeria, Pelagia Research Library, AASRFC Advances in Applied Science Research, 1(2), 2011, 163-177.

[15] N.A Alridha, I.A Ameen, and M.S.K Wadhah, The Role of (Geoelectric and Hydrogeologic) Parameters in the Evaluation of Groundwater reservoir at South of Jabal Sinjar area, Iraqi Journal of Science, 54(3), 2013, 628-637.

[16] R Sporry, Lecture material on Resistivity. Earth System Analysis Department, ITC, 2001.

[17] G.E Archie, The electrical resistivity $\log$ as an aid in determining some reservoir characteristics, Trans. Am. Inst. Min. Metal. and Petr. Eng., 146, 1942, 54-62.

[18] G.V Keller and F.C Frischknecht, Electrical methods in Geophysical Prospecting (New York: Pergamon Press, 1966).

[19] J. Bear, Dynamics of fluid in porous media (American Elsevier, New York, 1972).

[20] H.S Salem and G.V Chilingarian, Determination of specific surface area and mean grain size from well log-data and their influence on the physical behavior of offshore reservoirs, J. Pet. Sci. Eng., 22, 1999a, 241-252.

[21] H.S Salem, Determination of fluid transmissivity and electrical transverse resistance for shallow aquifers and deep reservoirs from surface and well-log electric measurements, Hydrology and Earth System Sciences, 3(3), 1999, 421-427.

[22] N. Sri and A.L.L Olivar, Technical note/ Aquifer Parameter Estimation from surface resistivity data, Groundwater, 41, (1), 2003, 94-99

[23] P. Wong, J. Koplick and J.P Tomanic, Conductivity and Permeability of Rocks, Phys. Rev, B. 30, 1984 , 6606-6614.

[24] B. Sosi, Hydraulic Characterization of the Kabatini Aquifer, Upper Lake Nakuru Basin, Kenya rift, Using Geophysical and Pumping Test Data, M.Sc Diss., University of Nairobi, Nairobi, Kenya, 2010.

[25] R.A Freeze and J.A Cherry, Groundwater (Prentice Hall Inc. Englewood Cliffs, New Jersey, 1979).

[26] C.R Fitts, Groundwater Science (Elsever Publications, the Netherlands, 2002).

[27] S.P Friedman, and N.A Seaton, A critical path analysis of the relationship between permeability and electrical conductivity of three-dimensional pore networks, Water Resources Research. 34(7), 1998, 1703-1710

[28] J.O Barongo, N. K Zachariah, and K.M Josphat, Geophysical Studies of the Shallow Structure beneath the Lake Nakuru Basin, Central Kenya Rift. International Symposium on the Hydrogeology of Volcanic Rocks, Djibouti, Republic of Djibouti 14th - 17th December, 2008.

[29] A.K Waswa, Geophysical mapping of buried river channels and other shallow structures recharging major aquifers in the lake nakuru basin, kenya rift: case study from kabatini aquifer, M.Sc Diss., University of Nairobi, Nairobi, Kenya, 2010. 